\title{
Modelling the Impact of Electricity Access on Labour Market Outcomes in Uganda
}

\section{Yannick Fosso Djoumessi ( $\nabla$ dyannickjugnor@yahoo.fr)}

University of Dschang: Universite de Dschang https://orcid.org/0000-0002-5245-5125

\section{Benjamin AWODUMI}

Nigerian Institute of Social and Economic Research

\section{Oluyemi ADEOSUN}

University of Lagos

\section{Faith AHABYOONA}

Uganda Technology and Management University

\section{Research}

Keywords: Electricity access, Impact, Labor market, PSM, Uganda

Posted Date: August 3rd, 2021

DOl: https://doi.org/10.21203/rs.3.rs-724560/v1

License: (c) (i) This work is licensed under a Creative Commons Attribution 4.0 International License. Read Full License 


\title{
Modelling the Impact of Electricity Access on Labour Market Outcomes in Uganda
}

\author{
Yannick Fosso DJOUMESSI* \\ ${ }^{1}$ Pan-African Scientific Research council | University of Dschang, Cameroon \\ Corresponding author’s email: dyannickjugnor@yahoo.fr, T: (+237) 674770704 \\ Olabanji Benjamin AWODUMI \\ ${ }^{2}$ Nigerian Institute of Social and Economic Research (NISER), Nigeria E: benawodumi@ gmail.com \\ Oluyemi Theophilus ADEOSUN \\ ${ }^{3}$ Department of Economics | University of Lagos, Nigeria | E: oluyemiadeosun@gmail.com \\ Faith AHABYOONA \\ ${ }^{4}$ Uganda Technology and Management University |E: ahabyoonaf@gmail.com
}

\begin{abstract}
This study is designed to assess the impact of household electricity access on labour market outcomes in Uganda. The quasi-experimental method is applied on a sample of 28,035 households, divided into two counterfactual of treatment $(n=8,925)$ and control $(n=19,110)$ groups. Results strongly show that access to electricity significantly increases wages while decreasing the time spent at work. Specifically, the average wage of the households with access to electricity increased by $155 \%, 124 \%$ and $154 \%$ with the Kernel Matching (KM), Nearest-Neighbor Matching (NNM) and Radius Matching (RM) technique, respectively. The average job duration of households with electricity access decreased by $1.34 \%, 2.01 \%$ and $2.5 \%$ with KM, NNM and RM technique, respectively. It is recommended that the government of Uganda should increase electricity generation coverage through alternative sources as renewable and nuclear energy and improve the quality of existing energy infrastructures.
\end{abstract}

Keywords: Electricity access, Impact, Labor market, PSM, Uganda

JEL codes: C13, C31 


\section{Introduction}

Historically, access to electricity has been identified as a key factor for growth and development. Developed and emerging economies relied substantially on the adequate supply of electricity to facilitate all industrial activities and enhance a conducive environment through the functioning of critical infrastructures (Elias and Victor 2005; Wolde-Rufael 2006; Tengbe, 2017). However, the electricity supply in Uganda has been known to be epileptic over the years due to absolute neglect from the government following the economic crisis and political instability in the country. In addition to the outbreak of Covid19 pandemic faced by the continent (Djoumessi, 2021).

According to the International Energy Agency (2017), over 1.1 billion people do not have access to electricity, and most of these people reside in rural areas. Inadequate access to electricity is often seen to limit people's opportunities and quality of life as electricity is one of the key drivers to sustainable development as widely recognised globally. In terms of labour market outcomes, household electrification tends to enhance labour productivity, raising wages as more leisure hours and unproductive loss of time, occasioned by lack of electricity, are directed towards productive activities. The link with job duration is still unclear as existing literature is yet to agree. On the one hand, increased access to electricity could increase leisure time as long hours of work may be reduced significantly to more productive few hours with a regular electricity supply (Rathi and Vermaar, 2018). Again, increased opportunities for lighting and the likelihood of equipment for work for longer hours could drive the motive to increase productivity and profit. This increase work hour with a regular supply of electricity can vary between males and females (Salmon and Tanguy, 2016). Also, long study hours are allowed, which further enhanced human capital development.

Economic growth in Uganda has been impressive, with positive growth performance in the last few decades and an average of $6.8 \%$ in 2019. This performance has been supported with low energy services (Hausmann et al., 2014). Moreover, due to energy deficits in the country, manufacturing industries are largely supported by international organisations such as the World Bank, especially in terms of access to alternative energies called power factor correction technologies (Okoboi and Mawejje 2016; World Bank, 2012). Ensuring access to affordable and reliable energy sources by all people has been one of the most significant Sustainable Development Goals (SDGs). However, Uganda faces a considerable problem of access to electricity with the 
lowest electricity consumption per capita in Africa, and the pain being particularly chronic in rural areas. The rate of access to electricity in Uganda is around 13.5\%, with an average consumption of $75 \mathrm{kWh}$ per year per inhabitant. As a comparison, this consumption is on average 12,000 kWh per year for an American and 7,344 kWh on average per year for a French person. For many households with access to electricity, reliability of supply and availability remain major problems. Thus, a particular emphasis on access to electricity and the labour market outcomes enhances our understanding of the causal links between electrification and well-being.

Small businesses and self-employed people dominate the Ugandan economy, and they also have a booming young population. The labour market in the country is mainly agrarian. Agriculture is one of the most critical sectors of the economy, employing $68.3 \%$ of the working population. The country's industrial sector is small and depends on imported goods such as refined petroleum and heavy equipment. Several supply-side constraints, including inadequate infrastructure, lack of modern technology and corruption, hamper productivity. This situation made rural energy access not a financially viable business investment for the private sector electricity distribution companies and their slow investment. These challenges, of course, will not only hinder the SDG agenda but retards inclusive growth for all Ugandans, and in most developing countries following Haselip and Hilson (2005). Given that most Ugandans are experiencing an unemployment crisis, the energy deficiency only makes this situation appalling. The share of employment in the secondary sector is around $7 \%$ of the active population. The service sector in Uganda employs $24.5 \%$ of the workforce. However, it is detached from the primary sectors, which limits the ability to stimulate economic growth. Employment in the primary sector remains largely more dominant in rural areas than in urban areas. Many people employed in rural areas work on their land or as a casual worker on other agricultural lands. Uganda also has a large informal economy, mainly in the agricultural sector. Self-employed and contributing family workers make up a large part of this informal economy. The lack of reliable and affordable electricity supply is a major obstacle to the growth of the informal sector, as it has important implications for employment, wages and job duration.

The preceding raises important questions, what impact does access to electricity have on labour market outcomes? Or, more specifically, do wage and job duration significantly differ between households with access to electricity and those without? Therefore, this study aims to provide answers to this question. Hence, it examines the impact of electricity access on labour market 
outcomes in Uganda, where there is a clear dearth of empirical investigation of this link. While several existing studies examined the link with various developmental and welfare outcomes such as education, health, poverty and income, very limited studies exist for the impact on labour market outcomes.

\section{Literature review}

Energy has become a critical input in modern production activities, as it facilitates the functioning of other factors of production such as capital and labour (Quesada-Pineda et al., 2016; Kurniawan and Managi, 2018; and Awodumi and Adewuyi, 2020). Access to energy, particularly for electricity generation, is a crucial element in human capital development by aiding the production of the conducive learning environment and production and maintenance of educational and health infrastructure, and ultimately promoting growth and development (Winkler et al., 2010; Rausch and Mowers, 2014; Asensio et al., 2019; Gyamfi et al., 2020; Sarkodie and Adams, 2020b). Thus, access to electricity directly leads to improved human development, which has important implications for labour market outcomes. Several studies have investigated the link between energy access and social and economic outcomes such as poverty (Lenz et al., 2016; MacDonald et al., 2020), income inequality (Sarkodie and Adams, 2020a and Sarkodie and Adams, 2020b), education (Olanrele et al., 2020), health (Irwin et al., 2019) and a combination of welfare outcomes (Khandker et al., 2013; Bridge et al., 2016; Esteban et al., 2018). A few others specifically consider the labour market outcomes of electricity access (Rathi and Vermaak, 2018; Salmon and Tanguy, 2016; Tagliapietra et al., 2020).

A review of 50 impact evaluation studies by Jimenez (2017) reveals substantial overall welfare gains through school enrollment, employment and incomes, which tends to be greatest for women and small firms. However, findings for African countries are mixed on the critical role of electricity access in welfare outcomes. For instance, in Sub-Saharan Africa, nonparametric analysis of Sarkodie and Adams (2020a) revealed a reducing effect of income inequality on access to electricity during the 1990-2017 period, but a positive impact of income level and human development have a positive impact on access to electricity. However, the Bayesian and nonlinear autoregressive distributed lag (NARDL) approach of Sarkodie and Adams (2020b) showed that income inequality significantly increased electricity access in the long run in South Africa between 1990 and 2017. Peters and Sievert (2017) found significant positive health, education and income 
effects in Africa due to rural electrification, though Lenz et al. (2016), who studied Rwanda's electricity roll-out programme, show evidence of weak impacts on poverty indicators, including income, health, and education. Again, focusing on Nigeria's rural communities in a logistic regression analysis, Olanrele et al. (2020) reported a significant reduction in children study hour with household access to grid electricity while expenditure on electricity decreases study hour by as much as $12 \%$.

For other regions, results largely corroborate the submission of Irwin et al. (2019), who found a positive impact of electrification on health outcomes ranging from lower disease rates, reduced mortality, and improved quality of life access to care. For the case of Vietnam, Khandker et al. (2013) adopted the fixed effect quantile regression to confirm the positive impact of household electrification on income, expenditure and school completion rates. Bridge et al. (2016) estimated a simultaneous equation using three-stage least squares, and they discovered that household's access to electricity in Nepal significantly enhance the quality of life by increasing income, educational attainment and agricultural productivity, though the impact on health is negligible. Using the same methods, Esteban et al. (2018) obtained similar results, while Alam et al. (2018) showed a long-run increasing impact of electricity access on labour productivity in a panel of 56 developing countries, with significant short-run bidirectional causal using FMOLS and Dumitrescu and Hurlin (2012) heterogeneous panel non-causality test during 1991-2013.

The link between electricity access and labour market outcomes has received some attention in the past decade, with mixed findings across various outcomes. For instance, probit and biprobit analysis of Tagliapietra et al. (2020) show significant and consistent shift out of agricultural employment to non-agriculture in Nigeria, positive overall labour participation effect. For this country, Salmon and Tanguy (2016) utilised the 2010-11 General Household Survey to show the increasing effect of rural electrification on the working time of both spouses when separate assessments are considered. However, their joint analysis reveals a positive effect only on husbands' working time. This gender dimension is also emphasised by Rathi and Vermaak (2018), where women who work are reported to benefit most from rural electrification in South Africa. They further found a significant reduction in working hours for both gender in India, though annual incomes are raised for both genders who work in paid employment. 
The preceding reveals a dearth of an empirical study on the electricity access-labour market nexus in Uganda. Energy access is perceived as a consumption good with expensive upfront connection costs that discourage users predominantly rural set-ups (Peters et al. 2009; Bernard, 2010; Scott et al. 2013). The energy sector in Uganda is governed by the 2002 energy policy, which is to meet the energy needs of the population for social and economic development in an environmentally sustainable manner. Despite several laudable government policies and the rural electrification strategy that saw the commissioning of about 38 projects in the rural areas, no evidence of solid labour market effects and energy deficiency exists. Moreover, existing studies in this area ignore the potential differences in labour market outcomes between those with access to electricity and those without. Apart from Uganda's context, this study fills the literature gaps at two levels: (i) two outcomes of labour market is considered, wage and job duration; and then (ii) the impact is modelled using a quasi-experimental approach based on the propensity score matching.

\section{Methodology}

To address the objective of the study, which is to assess the impact of electricity access on labour market outcomes, an impact evaluation method is employed. The literature distinguishes experimental or semi-experimental and non-experimental method of impact evaluation. Indeed, the experimental method requires analysis to be done before and after a given program (or intervention), which is not very common with secondary data. Whereas, in the case of the nonexperimental method, the impact is measured while comparing the results of two groups. The first group, set as a control group (households without access to electricity) resembling as much as possible the treated group (households with access to electricity) in terms of characteristics observed. Several methods can be used to construct our control group, matching method (the Propensity Score Matching), Difference in Difference on longitudinal data, Regression Discontinuity, and Instrumental variables. The Propensity Score Matching (PSM) is applied in this case. Kamdem (2018) argues the fact that the PSM technique removes bias due to the household's characteristics.

\subsection{Propensity Score Matching framework}

The PSM originally formulated by Rosenbaum and Rubin (1983), consists in building a group of statistical comparison based on the probability of having "access to electricity" (treatment), constraint to pretreatment household's characteristics: 


$$
p(X)=\operatorname{Pr}(T=1 \mid X)=E(T \mid X)
$$

For each household $i$, we have $T$ as $\left(\begin{array}{c}T_{i}=1 \text { if the household has access to electricity } \\ T_{i}=0 \text { if the household does not have access to electricity }\end{array}\right)$.

The treatment effect is measured by the outcome variable $Y i,\left(\begin{array}{c}Y_{T i} \text { if } T=1 \\ Y_{N T i} \text { if } T=0\end{array}\right)$.

$Y_{T i}$ and $Y_{N T i}$ are the potential results in the two counterfactual situations of treatment and no treatment, respectively. Consider xi the pretreatment characteristics of household $i$, and if the propensity score $p\left(x_{i}\right)$ is known, then the average effect of treatment on the Treated (ATT) group can be estimated as:

$$
\begin{aligned}
\varphi & =E\left[Y_{T i}-Y_{N T i} \mid T_{i}=1\right]=E\left[E\left\{Y_{T i}-Y_{N T i} \mid T_{i}=1, p\left(x_{i}\right)\right\}\right] \\
& =E\left[E\left\{Y_{T i} \mid T_{i}=1, p\left(x_{i}\right)\right\}-E\left\{Y_{N T i} \mid T_{i}=0, p\left(x_{i}\right)\right\} \mid T_{i}=1\right]
\end{aligned}
$$

The outer expectation is over the distribution of $\left(p\left(x_{i}\right) \mid T_{i}=1\right), Y_{T i}$ and $Y_{N T i}$. According to Rosenbaum and Rubin (1983), the estimation of ATT is conditional to two main hypotheses:

Hypothesis 1 Balancing of pretreatment variables given the propensity score $p\left(x_{i}\right)$. This means that access to electricity is random for a given $p\left(x_{i}\right)$, and then households in both groups (treated and control) should be on average observationally identical.

Hypothesis 2 Unconfoundedness given the propensity score $p\left(x_{i}\right)$.

\subsection{Estimation techniques}

The PSM is done through a Probit or Logit model while controlling all the characteristics variables $\mathrm{X}$ that affect the "possibility of having access to electricity" and "labour market outcomes" variables. Heckman (1997) highlighted that estimators of PSM are more robust when X includes variables that affect the treatment and outcomes. However, the PSM estimate is not sufficient to assess the ATT. Since $p\left(x_{i}\right)$ is a continuous variable, the probability of observing two households with exactly the same value of the propensity score is zero (Becker and Ichino, 2002). There are four widely used techniques to overcome this issue: Nearest-Neighbor Matching, Radius Matching, Kernel Matching, and Stratification Matching. 
In the case of the Nearest-Neighbor Matching, a controlled household can be the best match for more than one treated household. The difference between treatment and control outcomes is assessed when each treated household is matched with a controlled household. The ATT is obtained as the average of these differences, as follow:

$$
\varphi=\frac{1}{N_{T}} \sum_{i \in T}\left[Y_{T i}-\sum_{j \in C(i)} W_{i j} Y_{C j}\right]
$$

Where $N_{T}$ represents the number of treated household, C(i) is the set of controls matched to treated household $i, N_{C i}$ represents the number of controls matched to treated household $i$, and $W_{i j}=$ $\frac{1}{N_{C i}}$ if $j \in C(i), 0$ otherwise. However, this method presents the limit of producing very poor matches. If The Radius and Kernel Matching offer conditions to overcome this problem, they also present some limits on the dimension of the neighbourhood. Becker and Ichino (2002) concluded that none of these four methods is a priori superior to the others, and they all give appropriate estimates of the ATT.

\subsection{Data collection and source}

To assess the impact of electricity access on labour market outcomes in Uganda, we collected data from the Living Standards Measurement Survey - Integrated Surveys in Agriculture (LSMS-ISA) ${ }^{1}$ Dataset provided by the World Bank for Uganda. The variables on household characteristics who worked during the last year of the survey, variables on electricity access and labour market outcomes, mainly: wage and job duration, are generated from the most recent LSMS-ISA dataset for Uganda (2017-2018 National Household Survey). The total sample is 28,035 households who worked during the last year of the survey. Indeed, the study mainly focuses on two outcomes of the labour market: wage and duration. This total sample is divided into two counterfactual treatments $(8,925$ households) and control (19,110 households), respectively.

The household's characteristics variables include covers age, type of education, gender and location. Age of household head is measured as the number of years old; type of education, a dummy variable that takes 1 if the household head attended formal school, and 0 otherwise; gender,

${ }^{1}$ https://www.worldbank.org/en/programs/Isms/initiatives/Isms-ISA\#acc46 
a dummy variable that takes 1 if the household head is male, and 0 otherwise. Location is also a dummy variable taking up 1 if the household is located in a rural area and 0 otherwise (urban or peri-urban). The outcome variables include: Wage, which is the payment rate of job in local currency; and job duration, is the total period of working, in months, during the last year of the survey. The treatment variables, access to electricity, is a dummy variable which is 1 if the household has access to electricity and 0 otherwise. More details on the data are given in Table 1.

Table 1: Statistics on variables used

\begin{tabular}{|c|c|c|c|c|c|c|c|}
\hline Type & Variables & Obs. & Mean & Freq. & Per. (\%) & Min & Max \\
\hline \multirow[t]{10}{*}{$\begin{array}{l}\text { Household } \\
\text { characteristics }\end{array}$} & Age & 28,035 & $\begin{array}{c}31.93176 \\
(17.59802)\end{array}$ & & & 0 & 92 \\
\hline & Formal School & 28,035 & & & & & \\
\hline & $\mathrm{No}=0$ & & & 4,432 & 15.81 & & \\
\hline & Yes $=1$ & & & 23,603 & 84.19 & & \\
\hline & Gender & 28,035 & & & & & \\
\hline & Female $=0$ & & & 12,822 & 45.74 & & \\
\hline & Male $=1$ & & & 15,213 & 54.26 & & \\
\hline & Rural & 28,035 & & & & & \\
\hline & $\mathrm{No}=0$ & & & 12,892 & 45.99 & & \\
\hline & Yes $=1$ & & & 15,143 & 54.01 & & \\
\hline \multirow[t]{2}{*}{$\begin{array}{l}\text { Outcome } \\
\text { variables }\end{array}$} & Job duration & 28,035 & $\begin{array}{c}9.23196 \\
(3.631294)\end{array}$ & & & 1 & 12 \\
\hline & Wage & 28,035 & $\begin{array}{c}193933 \\
(313010)\end{array}$ & & & 1000 & 5000000 \\
\hline $\begin{array}{l}\text { Treatment } \\
\text { variable }\end{array}$ & $\begin{array}{l}\text { electricity } \\
\mathrm{No}=0 \\
\mathrm{Yes}=1\end{array}$ & 28,035 & & $\begin{array}{c}19,110 \\
8,925\end{array}$ & $\begin{array}{l}68.16 \\
31.84 \\
\end{array}$ & & \\
\hline
\end{tabular}

Standard errors are in parentheses, Source: Authors' calculations using Uganda National Survey data (2018).

\section{Results and discussion}

\subsection{Summary Statistics}

The descriptive statistics of the variables used in the analysis are presented in Table 2. The average age of respondents for the full sample is 32 years, ranging from 30 years in the treatment sample to 33 years in the non-treatment sample. Also, the mean wages in the total sample are 193,933 Ugandan shillings but can be as low as 122,759 Ugandan shillings and as high as 346,330 Ugandan shillings between households without electricity access those with access respectively. The 
average job duration is nine months, which is also consistent across the treatment and control groups. The distribution of the covariates for both the treatment and control samples are not significantly different for most of the variables, indicating a random distribution of the variables.

Table 2: Descriptive statistics by the sample group

\begin{tabular}{lcccccc}
\hline & \multicolumn{2}{c}{ Total sample } & \multicolumn{2}{c}{ Treatment sample } & \multicolumn{2}{c}{ Non-treatment sample } \\
& \multicolumn{2}{c}{ (28,035 observations $)$} & \multicolumn{2}{c}{$(8,925$ observations $)$} & \multicolumn{2}{c}{ (19,110 observations $)$} \\
\cline { 2 - 6 } \multicolumn{1}{c}{ Variable } & Mean & Std. Dev. & Mean & Std. Dev. & Mean & Std. Dev. \\
\hline Age & 31.932 & 17.598 & 30.245 & 14.954 & 32.720 & 18.654 \\
Formal school & 0.842 & 0.365 & 0.970 & 0.171 & 0.782 & 0.413 \\
Sex & 0.543 & 0.498 & 0.445 & 0.497 & 0.588 & 0.492 \\
Rural & 0.540 & 0.498 & 0.191 & 0.393 & 0.703 & 0.457 \\
Wage & 193933.0 & 313010.0 & 346329.5 & 451027.8 & 122758.8 & 181165.9 \\
Job duration & 9.232 & 3.631 & 9.389 & 3.621 & 9.159 & 3.634 \\
Treatment (Electricity) & 0.318 & 0.466 & & & & \\
\hline
\end{tabular}

Source: Authors' calculations using Uganda National Survey data (2018).

\subsection{Electricity Access and Labour Market Outcomes}

Analysis in this study is conducted in three steps. First, a Probit model is used to estimate the propensity score. Then, the average treatment effect is estimated using the Kernel matching; and lastly, some tests are conducted to satisfy the balance of matched samples. The results of the Probit regressions used to estimate the propensity scores related to electricity access are presented in Table 3. The model exhibits strong and satisfactory explanatory power, as indicated by the Pseudo $\mathrm{R}^{2}$, which is as high as $25 \%$.

The results show that age and its square, sex, education and location are significant drivers of electricity access. In particular, the coefficients of age and its square are significant but negative and positive, respectively. Thus, the probability of having access to electricity decreases significantly as age increases. However, as a household grows beyond certain ages, the likelihood of access to electricity rises. This may indicate the priority for the industrial sector, where electricity demand exceeds $60 \%$, rather than residential and educational sectors with the dominance of young households. Expectedly, the probability of electricity access depends significantly on the type of education and location of households. For instance, estimates show that households with formal education have a higher probability of having access to electricity than those without formal education. 
In comparison, the probability is lower in the rural areas than in the urban centres. This suggests that while urban centres have higher electricity demand than rural areas following the high concentration of industries, commercial outlets and other public infrastructures that require energy input. This is plausible given the quest for industrialization and economic prominence in African countries (Ateba et al, 2019). Again, households with formal education are concentrated in urban areas and dominate the industrial sectors reflecting their higher probability of access to electricity. The likelihood of having access to electricity is also significantly higher for females than males.

Table 3: Estimation of the probability propensity score

\begin{tabular}{lc}
\hline Variables & Coefficient \\
\hline Age & $-0.011^{* * *}$ \\
Age2 & $(0.002)$ \\
& $0.00007^{* *}$ \\
sexe1 & $(0.00003)$ \\
& $-0.543^{* * *}$ \\
Formal school & $(0.018)$ \\
& $1.128^{* * *}$ \\
Rural & $(0.036)$ \\
& $-1.326^{* *}$ \\
Constant & $(0.018)$ \\
& $-0.329 * * *$ \\
& $(0.040)$ \\
Number of obs & \\
LR chi2(5) & 28,035 \\
Pseudo R2 & $8906.01 * * *$ \\
Log-likelihood & 0.254 \\
\hline
\end{tabular}

***Significant at $1 \%$ level; $* *$ Significant at $5 \%$ level; Standard errors are in parentheses. Source: Authors' calculations using Uganda National Survey data (2018).

The matching estimates of the average treatment effect of electricity access on the treated (ATT) are reported in Table 4. Using the Kernel approach, the results show that access to electricity tends to increase wage but reduce job duration after matching households who have access with households having similar characteristics with them but have no access. Specifically, the average wage of the households with access to electricity increased significantly over those without access (control) by 210,608.86 Ugandan shillings, while average job duration declined by 0.12 months. This finding is plausible as electricity access enhances productivity by reducing time spent on unproductive activities and leisure occasioned by inadequate electricity supply. It also reduces the 
time and cost of switching to alternative energy sources and the cost of maintenance. While some households without access find a safe haven in farming as an alternative source of income, most people seek alternative employment that requires less energy but are less productive in real terms. For instance, the surge in the number of "boda boda" (commercial) motorcycles and taxi operators may be linked to lack of electricity access. Energy access, therefore, influence productivity. Since productivity is directly linked to wages, access to electricity matters for increased wages. With electricity access, less time is required to produce the same or more quantity than a household without access, given that they have similar characteristics. Thus, electricity access may reduce overtime jobs and time spent on a task and consequently reduce job duration.

In an unmatched situation, a statistically significant difference between treated and control groups is found. Thus, access to electricity significantly increase wages and job duration by about $223,570.63$ and 0.23 , respectively. The reduction in job duration may stem from the tendency to work for more hours as a result of the opportunity afforded by an increased power supply. This tends to reduce leisure and increase work hours.

Table 4: Average impact of Grid electricity on labour market outcomes with Kernel

\section{The average effect of grid electricity on wage}

\begin{tabular}{lllcrrr}
\hline & & & & & \multicolumn{2}{c}{ T- } \\
Variable & Sample & Treated & Controls & Difference & S.E. & stat \\
\hline Wage & Unmatched & 346329.47 & 122758.84 & 223570.63 & 3784.45 & 59.08 \\
& ATT & 346329.47 & 135720.61 & 210608.86 & 5510.45 & 38.22 \\
\hline
\end{tabular}

Average effect of grid electricity on job duration

\begin{tabular}{llrrrrr}
\hline & & & & & \multicolumn{2}{c}{ T- } \\
Variable & Sample & \multicolumn{1}{c}{ Treated } & Controls & Difference & S.E. & \multicolumn{2}{c}{ stat } \\
\hline job_duration & Unmatched & 9.389 & 9.159 & 0.230 & 0.047 & 4.94 \\
& ATT & 9.389 & 9.517 & -0.128 & 0.067 & -1.91 \\
\hline
\end{tabular}

Note: S.E. does not take into account that the propensity score is estimated.

Source: Authors' calculations using Uganda National Survey data (2018).

A balancing test is conducted to check that household characteristics did not significantly vary between the treatment and control groups. As presented in Table 5, a substantial bias reduction between the matched and unmatched covariates are observed. Test results show that the standardised mean difference for overall covariates to obtain the propensity score reduced from about $60 \%$ before matching to about $3 \%$ after matching. Consequently, total bias substantially reduced from $44 \%$ to $2.5 \%$ after matching. The likelihood ratio tests reveal that the joint significance of covariates was rejected before and after matching. Also, the pseudo- $\mathrm{R}^{2}$ fell 
significantly from about $25 \%$ to about $0.1 \%$ before and after matching, respectively. Overall, test results suggest that differences in observable characteristics between households with and without access to electricity are successfully eliminated. This balance of the matched sample with the Kernel approach is plotted in Figure 1.

Table 5: Test on the balance of the matched samples with Kernel

\begin{tabular}{|c|c|c|c|c|c|c|c|c|}
\hline \multirow[b]{2}{*}{ Variable } & \multirow{2}{*}{$\begin{array}{c}\text { Unmatched } \\
\text { Matched }\end{array}$} & \multicolumn{2}{|c|}{ Mean } & \multirow[b]{2}{*}{$\%$ bias } & \multirow{2}{*}{$\begin{array}{l}\text { \%reduct } \\
\text { bias }\end{array}$} & \multicolumn{2}{|c|}{ t-test } & \multirow{2}{*}{$\begin{array}{l}\mathrm{V}(\mathrm{T}) / \\
\mathrm{V}(\mathrm{C})\end{array}$} \\
\hline & & Treated & Control & & & $\mathrm{t}$ & $\mathrm{p}>\mathrm{t}$ & \\
\hline \multirow[t]{2}{*}{ Sexe } & $\mathrm{U}$ & 0.445 & 0.588 & -29.1 & & -22.73 & 0 & . \\
\hline & M & 0.445 & 0.420 & 5 & 82.8 & 3.33 & 0.001 & . \\
\hline \multirow[t]{2}{*}{ Age } & $\mathrm{U}$ & 30.245 & 32.72 & -14.6 & & -10.99 & 0 & $0.64 *$ \\
\hline & M & 30.245 & 30.661 & -2.5 & 83.2 & -1.99 & 0.046 & $1.36^{*}$ \\
\hline \multirow[t]{2}{*}{ Formal_school } & $\mathrm{U}$ & 0.970 & 0.782 & 59.4 & & 41.33 & 0 & . \\
\hline & M & 0.970 & 0.962 & 2.6 & 95.7 & 2.98 & 0.003 & . \\
\hline \multirow[t]{2}{*}{ Rural } & $\mathrm{U}$ & 0.191 & 0.703 & -120.4 & & -91.44 & 0 & . \\
\hline & $\mathrm{M}$ & 0.191 & 0.185 & 1.2 & 99 & 0.9 & 0.37 & . \\
\hline \multicolumn{9}{|c|}{$*$ if variance ratio outside $[0.96 ; 1.04]$ for $\mathrm{U}$ and $[0.96 ; 1.04]$ for $\mathrm{M}$} \\
\hline Sample & Ps R2 & $\begin{array}{l}\text { L.R. } \\
\text { chi2 }\end{array}$ & $\mathrm{p}>\mathrm{chi} 2$ & MeanBias & MedBias & B & $\mathrm{R}$ & $\%$ Var \\
\hline Unmatched & 0.254 & 8898.57 & 0 & 55.9 & 44.2 & $138.3^{*}$ & 0.73 & 100 \\
\hline Matched & 0.001 & 30.29 & 0 & 2.8 & 2.5 & 8.2 & 0.68 & 100 \\
\hline
\end{tabular}

Source: Authors' calculations using Uganda National Survey data (2018).

Figure 1: Balance of the matched sample with Kernel 


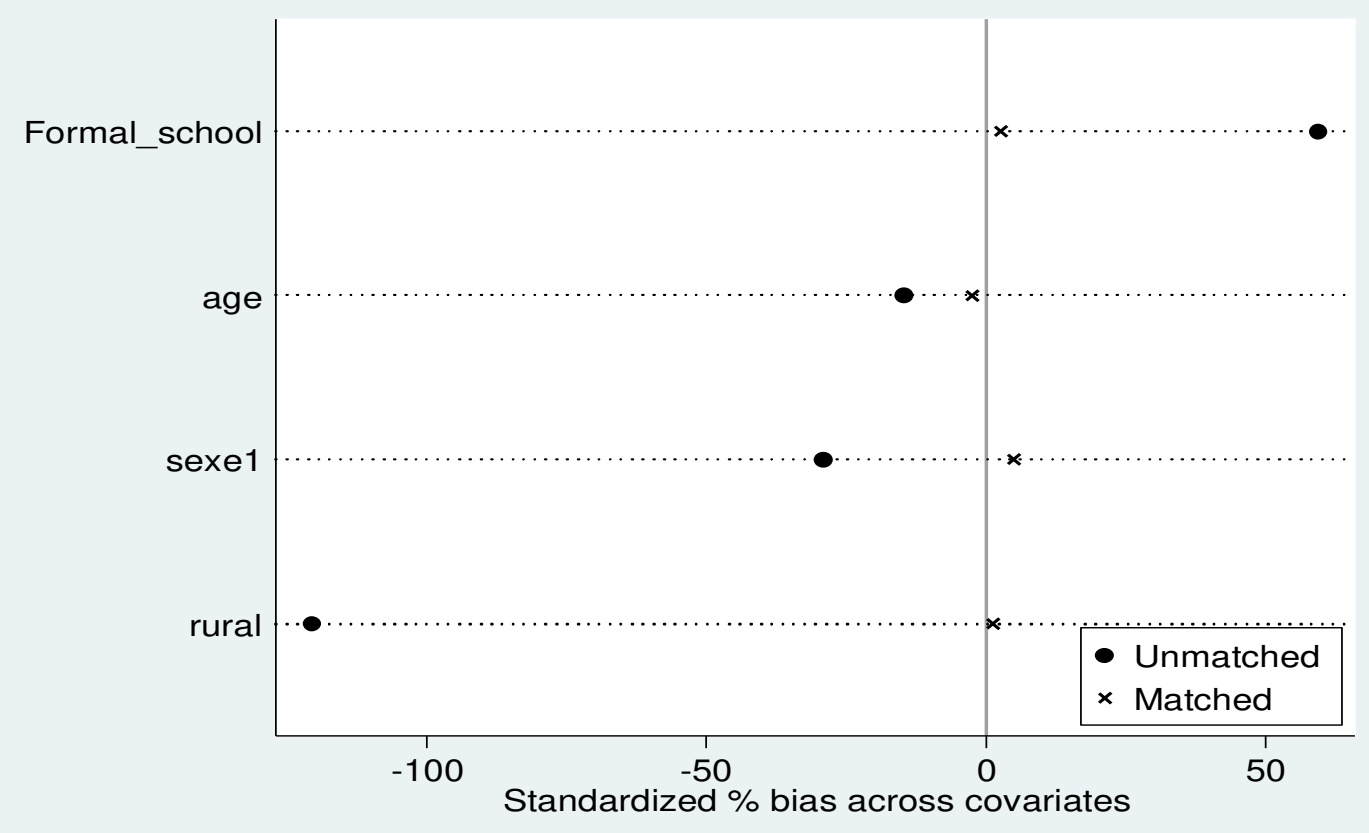

Source: Authors using Uganda National Survey data (2018).

The histogram showing the estimated propensity scores for households with access to electricity and those without is presented in Figure 2. The bottom half of the graph is the propensity score distribution for the households without access to electricity, while the upper half represents those with access. The densities of these scores are plotted on the y-axis. Substantial overlap is observed in the distribution of the propensity scores of both the treated (with access) and the control (without access) groups implying that the common support condition is satisfied.

\subsection{Robustness check with the other matching estimators}

The robustness of these findings is checked using alternative matching estimators, such as the nearest-neighbour and radius matching techniques. Results of the average impact of access to grid electricity on wages and job duration using the nearest-neighbour (Radius) approach are reported in Table 6 (Table 8). Similar to results obtained in the Kernel model, electricity access raised wages but reduced job duration following the matching of households. However, the increase in the average wage of the households with access to electricity over those without access is lower (191,751.93 Ugandan shilling) in the nearest-neighbour method but higher (211718.80 Ugandan shillings) when the radius approach was used. In contrast, while average job duration declined significantly by 0.24 months under the radius approach, the reduction 0.19 months, although this 
difference is not statistically significant. In the unmatched model, household wages and duration tend to increase significantly with electricity access with the same statistically significant difference over the control group, as obtain in the Kernel estimates.

Figure 2: Propensity score histogram by treatment status

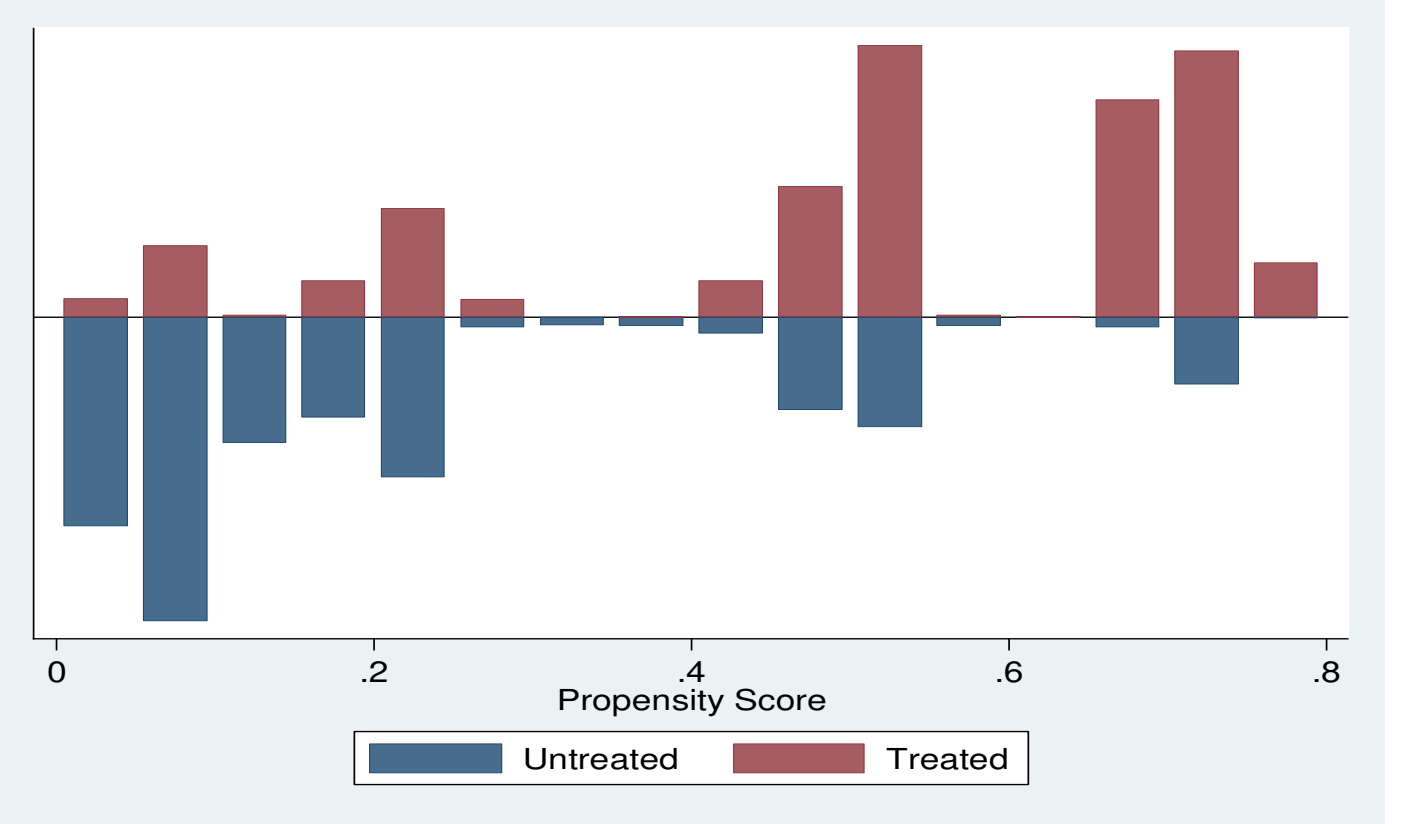

Source: Authors, using Uganda National Survey data (2018).

The balancing tests, presented in Table 7 and Table 9 for nearest-neighbour and Radius techniques, also yield similar statistics indicating a substantial bias reduction in the covariates. The overall covariates standardised mean difference declined from about 56\% (using both methods) before matching to $0.7 \%$ and $3.3 \%$ under nearest-neighbour and radius methods, respectively, after matching. This leads to noticeable reduction in total bias from $44 \%$ to $0.7 \%$ (nearest-neighbour) and from $44 \%$ to $3.3 \%$ (radius) after matching. Also, the likelihood ratio and pseudo- $\mathrm{R}^{2}$ indicate that differences in observable characteristics between the treated and control groups are removed. This is also revealed in Figures 3 and 4 for nearest-neighbour and radius, respectively.

These findings corroborate those reported by a number of studies. The positive influence of electricity access on wages is in line with Khandker et al. (2013), who discovered that household electrification raises income by as much as $28 \%$ and Rathi and Vermaar (2018) who found an increasing effect of electrification on annual incomes of paid employment workers in India and South Africa. Again, evidence of reducing the effect of electricity access on job duration is supported by Rathi and Vermaar (2018) in the case of India, where electricity improves 
productivity and reduces working hours. The positive electricity access effect on job duration in the unmatched situation may reflect individual characteristics. This is consistent with the findings of Salmon and Tanguy (2016), who reports that while electrification increases the working time of both spouses when separate assessments are considered, it only raises husbands' working time in a joint analysis.

\section{Conclusion}

The objective of this study was to estimate the impact of electricity access on labour market outcomes in Uganda. The Average effect of treatment on the Treated (ATT) is estimated with the Kernel Matching (K.M.) technique, and then with Nearest-Neighbor Matching (NNM) and Radius Matching (R.M.) for robustness check. First, the results strongly show that the average wage of the households with access to electricity increased by 155\%, 124\% and 154\% with K.M., NNM and R.M. technique, respectively. In other words, access to electricity ensures workers a wage at least two times higher than those without access to electricity in Uganda. These results align with Khandker et al. (2013) and Rathi and Vermaar (2018), who found an increasing effect of electrification on incomes of workers in India and South Africa. Then, the results strongly show that the average job duration for household with access to electricity decreased by $1.34 \%, 2.01 \%$ and $2.5 \%$ with K.M., NNM and R.M. technique, respectively. Indeed, a good and affordable energy source is an important time-saving factor. To promote inclusive growth, the government of Uganda has to: (i) increase the coverage of electricity generation through renewable energy and nuclear energy sources, and (ii) improve the quality of existing infrastructures for electricity generation.

\section{Declarations}

Ethics approval: Do no harm.

Consent to participate: participation is voluntary and potential participants are free to refuse consent.

Consent for publication: Informed consent.

Availability of data and materials: Living Standards Measurement Survey - Integrated Surveys

in Agriculture (LSMS-ISA), https://www.worldbank.org/en/programs/Isms/initiatives/Isms-ISA\#acc46.

Funding: No funding.

Authors' contributions: YF Djoumessi did the methodology, results, conclusion and abstract; OB AWUDOMI did the discussion of the results; OT ADEOSUN did the literature review; and F AHABYOONA did the introduction. 


\section{Conflict of Interest}

There is no conflicts of interest among authors.

\section{Acknowledgement}

The authors are grateful to the Africalis Acadamy, which has greatly contributed to guide and complete this article.

\section{References}

Alam M. S., Miah M. D., Hammoudeh D. and Tiwari A. K. (2018). The nexus between access to electricity and labour productivity in developing countries. Energy Policy, 122: 715-726.

Ateba B. B., Prinsloo J. J. and Gawlik R. (2019). The significance of electricity supply sustainability to industrial growth in South Africa. Energy Reports, 5: 1324-1338.

Awodumi O. B. and Adewuyi A. O. (2020). The role of non-renewable energy consumption in economic growth and carbon emission: Evidence from oil-producing economies in Africa Energy Strategy Reviews, 100434, https://doi.org/10.1016/j.esr.2019.100434.

Becker, S. O., \& Ichino, A. (2002). Estimation of Average Treatment Effects Based on Propensity Scores. The Stata Journal: Promoting Communications on Statistics and Stata, 2(4), 358-377. https://doi.org/10.1177/1536867X0200200403.

Bridge B. A., Adhikari D. and Fontenla M. (2016). Electricity, income, and quality of life. The Social Science Journal, 53: 33-39.

Djoumessi, Y.F. (2021), "The adverse impact of the Covid-19 pandemic on the labor market in Cameroon", African Development Review, Wiley Online Library, Vol. 33, pp. S31-S44.

Esteban A. F. L., Kafarov V. V., Guerrero I., Cortes A., Cerón A. M. R., Duarte M. M. (2018). Assessment of Access to Electricity and the Health, Education and Agricultural Productivity Effects in Rural Areas of Colombia. Chemical Engineering Transactions, 70: 1219-1224.

Gyamfi, B.A., Bein, M.A. \& Bekun, F.V. Investigating the nexus between hydroelectricity energy, renewable energy, nonrenewable energy consumption on output: evidence from E7 countries. Environ Sci Pollut Res 27, 25327-25339 (2020). https://doi.org/10.1007/s11356-020-08909-8.

Haselip, J, Hilson, G (2005) Winners and losers from industry reforms in the developing world: experiences from the electricity and mining sectors, Resources Policy, 30 (2): 87-100.

Hausmann R, Cunningham B, Matovu J, Osire R, Wyett K (2014) How should Uganda grow? Centre for international development (CID), working paper no. 275, Harvard College, ISSN 2211-467X,https://doi.org/10.1016/j.esr.2020.100480.

Heckman, J. (1997). Instrumental variables: A study of implicit behavioral assumptions used in making program evaluations. Journal of Human Resources, 441-462. 
Irwin B. R., Hoxha K. and Grépin K. A. (2019). Conceptualising the effect of access to electricity on health in low- and middle-income countries: A systematic review, Global Public Health, DOI: 10.1080/17441692.2019.1695873.

Jimenez R. (2017). Development Effects of Rural Electrification. Inter-American Development Bank, Infrastructure and Energy Sector, Energy Division, Policy Brief No: IDB-PB-261.

Lenz L., Munyehirwe A., Peters J., and Sievert M. (2016). Does Large-Scale Infrastructure Investment Alleviate Poverty? Impacts of Rwanda's Electricity Access Roll-Out Program. World Development, http://dx.doi.org/10.1016/j.worlddev.2016.08.003.

Kamdem, C. B. (2018). Farmer field schools and cocoa yield in Cameroon. Revue Deconomie Du Developpement, 26(4), 99-124.

Khandker S. R., Barnes D. F. and Samad H. A. (2013). Welfare Impacts of Rural Electrification: A Panel Data Analysis from Vietnam. Economic Development and Cultural Change, 61(3): 659692.

MacDonald, S., Winner, B., Smith, L. et al. (2020) Bridging the rural efficiency gap: expanding access to energy efficiency upgrades in remote and high energy cost communities, Energy Efficiency, 13: 503-521.

Okoboi G, Mawejje J (2016) The impact of adoption of power factor correction technology on electricity peak demand in Uganda. J Econ Struct 5(1):1-14.

Olanrele I. A., Lawal A. I., Dahunsi S. O., Babajide A. A. and IseOlorunkanmi J. O. (2020). The Impact of Access to Electricity on Education and Health Sectors in Nigeria's Rural Communities. Entrepreneurship and Sustainability Issues, 7(4): 3016-3035.

Peters J. and Sievert M. (2016). Impacts of rural electrification revisited -the African context, Journal of Development Effectiveness, DOI:10.1080/19439342.2016.1178320.

Quesada-Pineda, H., Wiedenbeck, J. and Bond, B. (2016) Analysis of electricity consumption: a study in the wood products industry, Energy Efficiency, 9: 1193-1206.

Raugh, S, Mowers, M, (2014) Distributional and efficiency impacts of clean and renewable energy standards for electricity, Resource and Energy Eonomics, 36(2): 556-585.

Rathi S. S. and Vermaak C. (2018). Rural electrification, gender and the labor market: A crosscountry study of India and South Africa.

Rosenbaum, P. R., \& Rubin, D. B. (1983a). Assessing sensitivity to an unobserved binary covariate in an observational study with binary outcome. Journal of the Royal Statistical Society: Series B (Methodological), 45(2), 212-218.

Rosenbaum, P. R., \& Rubin, D. B. (1983b). The central role of the propensity score in observational studies for causal effects. Biometrika, 70(1), 41-55.

Salmon C. and Tanguy T. (2016). Rural Electrification and Household Labor Supply: Evidence from Nigeria. World Development, 82: 48-68.

Sarkodie. S and Adams. S (2020a). Electricity access, human development index, governance and income inequality in Sub-Saharan Africa. Energy Reports, 6: 455-466. 
Sarkodie. S and Adams. S (2020b). Electricity access and income inequality in South Africa: Evidence from Bayesian and NARDL analyses, Energy Strategy Reviews, Volume 29, 100480

Tagliapietra S., Occhiali G., Nano E. and Kalcik R. (2020). The impact of electrification on labour market outcomes in Nigeria. Economia Politica, 37:737-779.

Tengbe. E (2017).Creating an Enabling Environment for Foreign Direct Investment in Renewable Energy through Law Reforms in Sierra Leone.

Winkler, H., Howells, M., \& Alfstad, T. (2005). South African energy policies for sustainable development. Report for the International Atomic Energy Agency. Cape Town: Energy Research Centre.

Wolde-Rufael Y (2006) Electricity consumption and economic growth: a time series experience for 17 African countries. Energy Policy 34:1106-1114.

World Bank (2012) Implementation completion and results report for power sector development operation (IDA-42970) report no.: ICR2159. The World Bank, Washington.

Table 6: Average impact of Grid electricity access on labor market outcomes with nearestneighbor

\begin{tabular}{|c|c|c|c|c|c|c|}
\hline \multicolumn{7}{|c|}{ Average effect of grid electricity on wage } \\
\hline Variable & Sample & Treated & Controls & Difference & S.E. & T-stat \\
\hline \multirow[t]{2}{*}{ Wage } & Unmatched & 346329.47 & 122758.84 & 223570.63 & 3784.451 & 59.08 \\
\hline & ATT & 346329.47 & 154577.54 & 191751.93 & 14914.239 & 12.86 \\
\hline \multicolumn{7}{|c|}{ Average effect of grid electricity on job duration } \\
\hline Variable & Sample & Treated & Controls & Difference & S.E. & T-stat \\
\hline \multirow[t]{2}{*}{ job duration } & Unmatched & 9.389 & 9.159 & 0.230 & 0.047 & 4.94 \\
\hline & ATT & 9.389 & 9.582 & -0.193 & 0.270 & -0.72 \\
\hline
\end{tabular}

Note: S.E. does not take into account that the propensity score is estimated.

Source: Authors' calculations using Uganda National Survey data (2018).

Table 7: Test on the balance of the matched samples with nearest-neighbor

\begin{tabular}{|c|c|c|c|c|c|c|c|c|}
\hline \multirow[b]{2}{*}{ Variable } & \multirow{2}{*}{$\begin{array}{l}\text { Unmatched } \\
\text { Matched }\end{array}$} & \multicolumn{2}{|c|}{ Mean } & \multirow[b]{2}{*}{$\%$ bias } & \multicolumn{2}{|c|}{ \%reduct } & test & \multirow{2}{*}{$\begin{array}{l}\mathrm{V}(\mathrm{T}) / \\
\mathrm{V}(\mathrm{C})\end{array}$} \\
\hline & & Treated & Control & & bias & $\mathrm{t}$ & $p>t$ & \\
\hline \multirow{2}{*}{ Sexe } & $\mathrm{U}$ & 0.445 & 0.588 & -29.1 & & -22.73 & 0.000 & . \\
\hline & M & 0.445 & 0.444 & 0 & 99.9 & 0.02 & 0.983 & \\
\hline \multirow[t]{2}{*}{ Age } & $\mathrm{U}$ & 30.245 & 32.72 & -14.6 & & -10.99 & 0.000 & $0.64 *$ \\
\hline & M & 30.245 & 30.439 & -1.1 & 92.2 & -0.88 & 0.379 & $1.07 *$ \\
\hline \multirow[t]{2}{*}{ Formal_school } & $\mathrm{U}$ & 0.970 & 0.782 & 59.4 & & 41.33 & 0.000 & . \\
\hline & $\mathrm{M}$ & 0.970 & 0.967 & 0.8 & 98.6 & 0.99 & 0.324 & . \\
\hline
\end{tabular}




\begin{tabular}{|c|c|c|c|c|c|c|c|c|}
\hline Rural & $\begin{array}{l}\mathrm{U} \\
\mathrm{M}\end{array}$ & $\begin{array}{l}0.191 \\
0.191 \\
\end{array}$ & $\begin{array}{l}0.703 \\
0.188 \\
\end{array}$ & $\begin{array}{c}-120.4 \\
0.6\end{array}$ & 99.5 & $\begin{array}{l}-91.44 \\
0.44\end{array}$ & $\begin{array}{l}0.000 \\
0.66\end{array}$ & \\
\hline \multicolumn{9}{|c|}{$*$ if variance ratio outside $[0.96 ; 1.04]$ for $\mathrm{U}$ and $[0.96 ; 1.04]$ for $\mathrm{M}$} \\
\hline Sample & Ps R2 & $\begin{array}{l}\text { L.R. } \\
\text { chi2 }\end{array}$ & $\mathrm{p}>\mathrm{chi} 2$ & MeanBias & MedBias & B & $\mathrm{R}$ & $\% \operatorname{Var}$ \\
\hline Unmatched & 0.254 & 8898.57 & 0.000 & 55.9 & 44.2 & $138.3^{*}$ & 0.73 & 100 \\
\hline Matched & 0.000 & 2.62 & 0.623 & 0.6 & 0.7 & 2.4 & 0.98 & 100 \\
\hline
\end{tabular}

$*$ if $\mathrm{B}>25 \%, \mathrm{R}$ outside $[0.5 ; 2]$

Source: Authors' calculations using Uganda National Survey data (2018).

Figure 3: Balance of the matched sample with nearest-neighbor

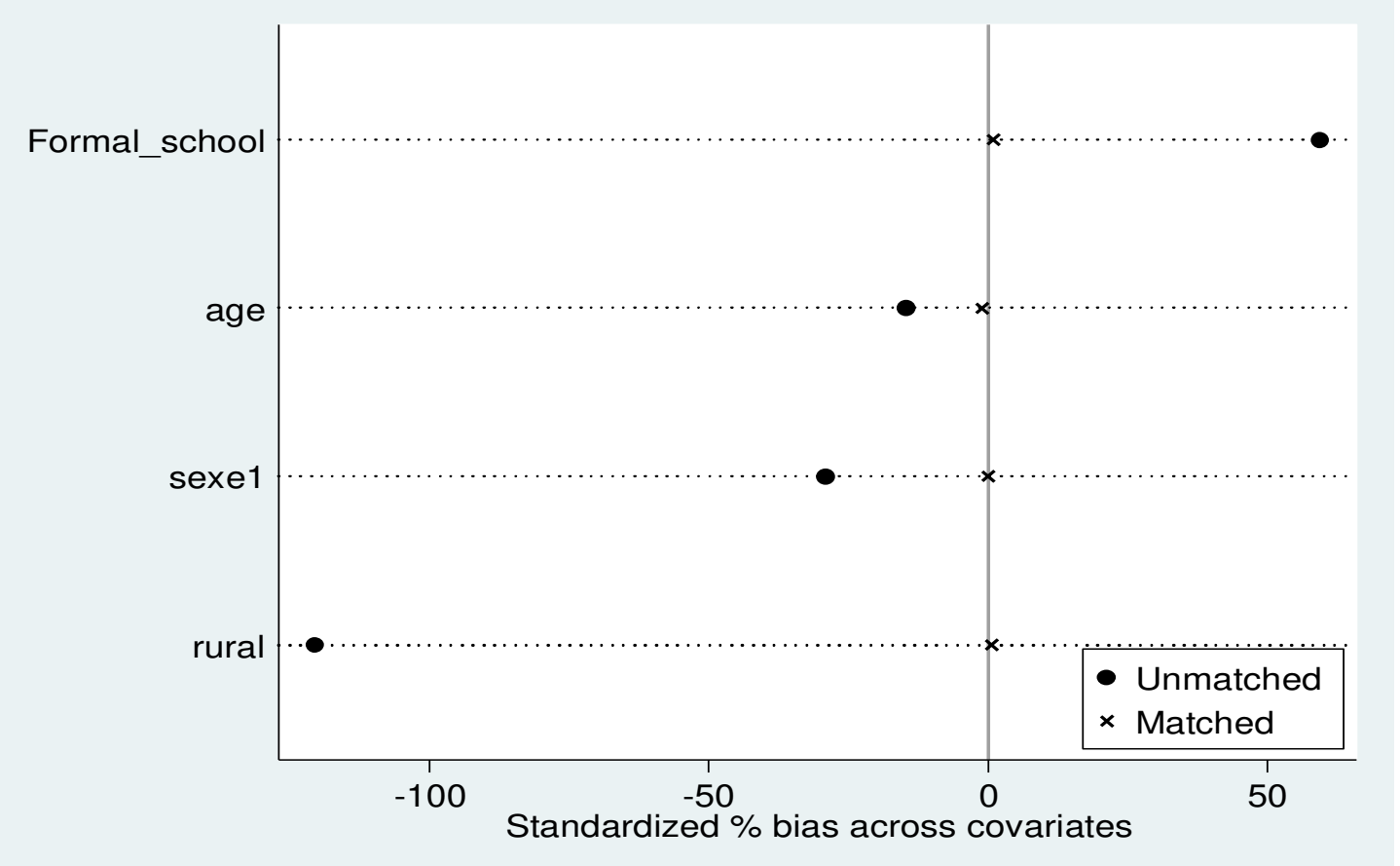

Source: Authors' using Uganda National Survey data (2018).

Table 8: Average impact of Grid electricity on labor market outcomes with radius

\begin{tabular}{llllllr}
\hline \multicolumn{2}{l}{ Average effect of grid electricity on wage } & & & \\
\hline Variable & Sample & Treated & Controls & Difference & S.E. & T-stat \\
\hline Wage & Unmatched & 346329.47 & 122758.837 & 223570.633 & 3784.451 & 59.08 \\
& ATT & 346329.47 & 134610.673 & 211718.797 & 5930.990 & 35.7
\end{tabular}




\begin{tabular}{llrrrrr}
\hline \multicolumn{2}{l}{ Average effect of grid electricity on job duration } & & & & \\
\hline Variable & Sample & Treated & Controls & Difference & S.E. & T-stat \\
\hline job_duration & Unmatched & 9.389 & 9.159 & 0.230 & 0.047 & 4.94 \\
& ATT & 9.389 & 9.633 & -0.244 & 0.080 & -3.04 \\
\hline
\end{tabular}

Note: S.E. does not take into account that the propensity score is estimated.

Source: Authors' calculations using Uganda National Survey data (2018).

Table 9: Test on the balance of the matched samples with radius

\begin{tabular}{|c|c|c|c|c|c|c|c|c|}
\hline \multirow[b]{2}{*}{ Variable } & \multirow{2}{*}{$\begin{array}{l}\text { Unmatched } \\
\text { Matched }\end{array}$} & \multicolumn{2}{|c|}{ Mean } & \multirow[b]{2}{*}{$\%$ bias } & \multicolumn{2}{|l|}{ \%reduct } & est & \multirow{2}{*}{$\begin{array}{l}\mathrm{V}(\mathrm{T}) / \\
\mathrm{V}(\mathrm{C})\end{array}$} \\
\hline & & Treated & Control & & bias & $\mathrm{t}$ & $p>t$ & \\
\hline \multirow[t]{2}{*}{ sexe1 } & $\mathrm{U}$ & 0.445 & 0.588 & -29.1 & & -22.73 & 0.000 & . \\
\hline & M & 0.445 & 0.421 & 4.8 & 83.6 & 3.18 & 0.001 & . \\
\hline \multirow[t]{2}{*}{ age } & $\mathrm{U}$ & 30.245 & 32.72 & -14.6 & & -10.99 & 0.000 & $0.64 *$ \\
\hline & M & 30.245 & 30.879 & -3.8 & 74.4 & -2.96 & 0.003 & $1.20^{*}$ \\
\hline \multirow[t]{2}{*}{ Formal_school } & $\mathrm{U}$ & 0.970 & 0.782 & 59.4 & & 41.33 & 0.000 & . \\
\hline & M & 0.970 & 0.961 & 2.8 & 95.2 & 3.27 & 0.001 & . \\
\hline \multirow[t]{2}{*}{ rural } & $\mathrm{U}$ & 0.19059 & 0.703 & -120.4 & & -91.44 & 0.000 & . \\
\hline & M & 0.19059 & 0.183 & 1.7 & 98.6 & 1.24 & 0.215 & \\
\hline \multicolumn{9}{|c|}{$*$ if variance ratio outside $[0.96 ; 1.04]$ for $\mathrm{U}$ and $[0.96 ; 1.04]$ for $\mathrm{M}$} \\
\hline Sample & Ps R2 & $\begin{array}{l}\text { L.R. } \\
\text { chi2 }\end{array}$ & p>chi 2 & MeanBias & MedBias & B & $\mathrm{R}$ & $\%$ Var \\
\hline Unmatched & 0.254 & 8898.57 & 0.000 & 55.9 & 44.2 & $138.3 *$ & 0.73 & 100 \\
\hline Matched & 0.002 & 37.73 & 0.000 & 3.3 & 3.3 & 9.2 & 0.65 & 100 \\
\hline
\end{tabular}

$*$ if $\mathrm{B}>25 \%, \mathrm{R}$ outside $[0.5 ; 2]$

Source: Authors' calculations using Uganda National Survey data (2018). 
Figure 4: Balance of the matched sample with radius

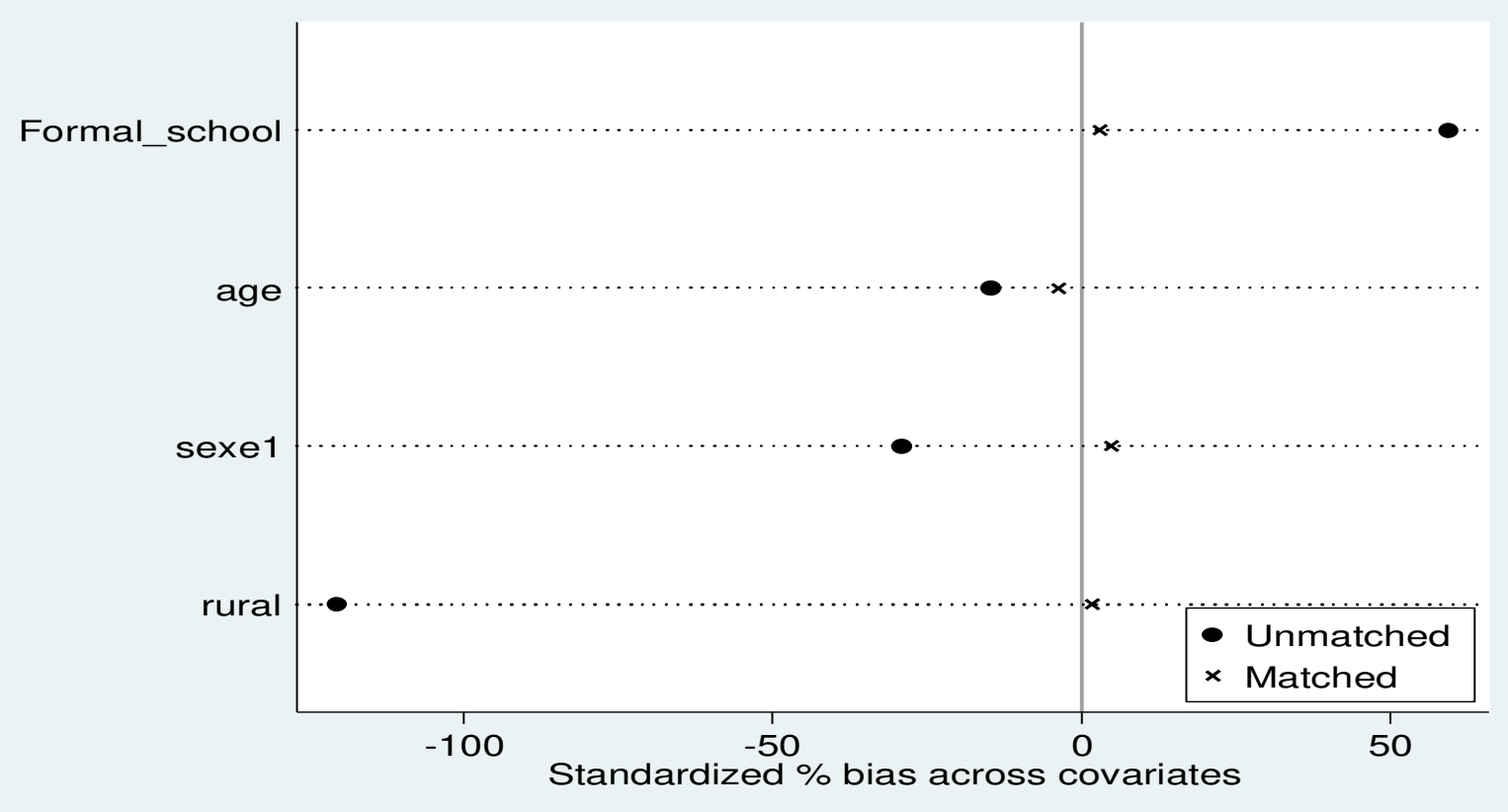

Source: Authors, using Uganda National Survey data (2018). 